ARTICLE

https://doi.org/10.1038/s41467-019-09224-8

\title{
Gas phase synthesis of [4]-helicene
}

\author{
Long Zhao', Ralf I. Kaiser (10) ${ }^{1}$, Bo Xu², Utuq Ablikim², Wenchao Lu², Musahid Ahmed (1) 2, Mikhail M. Evseev³, \\ Eugene K. Bashkirov ${ }^{3}$, Valeriy N. Azyazov ${ }^{3}$, Marsel V. Zagidullin ${ }^{3}$, Alexander N. Morozov ${ }^{4}$, A. Hasan Howlader ${ }^{4}$, \\ Stanislaw F. Wnuk (D) ${ }^{4}$, Alexander M. Mebel ${ }^{3,4}$, Dharati Joshi ${ }^{5}$, Gregory Veber ${ }^{5}$ \& Felix R. Fischer $5,6,7$
}

A synthetic route to racemic helicenes via a vinylacetylene mediated gas phase chemistry involving elementary reactions with aryl radicals is presented. In contrast to traditional synthetic routes involving solution chemistry and ionic reaction intermediates, the gas phase synthesis involves a targeted ring annulation involving free radical intermediates. Exploiting the simplest helicene as a benchmark, we show that the gas phase reaction of the 4phenanthrenyl radical $\left(\left[\mathrm{C}_{14} \mathrm{H}_{9}\right]^{*}\right)$ with vinylacetylene $\left(\mathrm{C}_{4} \mathrm{H}_{4}\right)$ yields [4]-helicene $\left(\mathrm{C}_{18} \mathrm{H}_{12}\right)$ along with atomic hydrogen via a low-barrier mechanism through a resonance-stabilized free radical intermediate $\left(\mathrm{C}_{18} \mathrm{H}_{13}\right)$. This pathway may represent a versatile mechanism to build up even more complex polycyclic aromatic hydrocarbons such as [5]- and [6]-helicene via stepwise ring annulation through bimolecular gas phase reactions in circumstellar envelopes of carbon-rich stars, whereas secondary reactions involving hydrogen atom assisted isomerization of thermodynamically less stable isomers of [4]-helicene might be important in combustion flames as well.

\footnotetext{
${ }^{1}$ Department of Chemistry, University of Hawaii at Manoa, Honolulu, HI 96822, USA. ${ }^{2}$ Chemical Sciences Division, Lawrence Berkeley National Laboratory, Berkeley, CA 94720, USA. ${ }^{3}$ Samara National Research University, Samara 443086, Russia. ${ }^{4}$ Department of Chemistry and Biochemistry, Florida International University, Miami, FL 33199, USA. ${ }^{5}$ Department of Chemistry, University of California, Berkeley, CA 94720, USA. ${ }^{6}$ Materials Sciences Division, Lawrence Berkeley National Laboratory, Berkeley, CA 94720, USA. ${ }^{7}$ Kavli Energy Nano Sciences Institute at the University of California Berkeley and the Lawrence Berkeley National Laboratory, Berkeley, CA 94720, USA. Correspondence and requests for materials should be addressed to R.I.K. (email: ralfk@hawaii.edu)
} 
$\mathrm{D}$ uring the last decades, helicenes-ortho-fused polycyclic aromatic hydrocarbons (PAHs), in which benzene building blocks are annulated at an angle of $60^{\circ}$ to form helically-shaped molecules ${ }^{1}-$ have received considerable attention from the organic ${ }^{2}$, and physical chemistry ${ }^{3}$, and material science communities ${ }^{4,5}$ due to their unique features in optics (chiroptical activity ${ }^{6}$, nonlinear optics ${ }^{3}$, and circular polarization $^{7}$ ) and chiral sensing (chemical sensors) ${ }^{8,9}$ along with exceptional properties in organocatalysis ${ }^{4,10,11}$ and distinctive molecular structures (Fig. 1) ${ }^{12}$. Considering the molecular structure of helicenes, the backbone twists in opposite directions due to the steric hindrance between the terminal rings. Within the helicene series, the dihedral angles between both terminal benzene moieties rises from [4]-helicene $\left(26^{\circ}\right)$ via [5]-helicene $\left(46^{\circ}\right)$ to [6]-helicene $\left(58^{\circ}\right)$ before it drops in [7]-helicene $\left(30^{\circ}\right)$. Helicenes are distinguished for their chirality despite missing asymmetric carbon atoms with the chirality developing from the handedness of the helix. Clockwise and counterclockwise helices are non-superimposable as the result of their axial chirality with a left- and right-handed helices being defined by minus (M) and plus $(\mathbf{P})^{13}$. The racemization mechanism depends on the size of the [n]-helicene involving a concerted process for $\mathrm{n}=4-7$, but a multistep mechanism for larger units. A single transition state with $\mathrm{C}_{2 \mathrm{v}}(n=4)$ and $\mathrm{C}_{\mathrm{s}}(n=5-7)$ symmetries and barriers increasing from about $17 \mathrm{~kJ} \mathrm{~mol}^{-1}$ via $102 \mathrm{~kJ} \mathrm{~mol}^{-1}$ and $154 \mathrm{~kJ}$ $\mathrm{mol}^{-1}$ to $176 \mathrm{~kJ} \mathrm{~mol}^{-1}$ connects the $\mathbf{M}$ and $\mathbf{P}$ forms $\mathrm{s}^{2,3,14-16}$.

The first helicene synthesis reported by Meisenheimer more than a century ago ${ }^{17}$ describes the formation of two aza-helicenes in the reduction of 2-nitronaphthalene with metallic zinc under basic conditions. The first carbohelicene, [5]-helicene, was synthesized only 15 years later by Weitzenböck and Klingler ${ }^{18}$ through copper-induced radical cyclization of 2-diazostilbenes. The larger homolog [6]-helicene ${ }^{19}$ was first obtained through intramolecular Friedel-Crafts cyclization of an acid chloride followed by reductive deoxygenation and rearomatization. While early synthesis of helicenes took advantage of an intramolecular oxidative photocyclization of readily accessible stilbenes ${ }^{20}$, a great variety of modern transformations have been applied. Among the most versatile are $[2+4]^{21-27}$ and $[2+2+2]$ cycloaddition reactions ${ }^{28-32}$, a variety of transition-metal catalyzed crosscoupling reactions ${ }^{33,34}$, and more recently ring closing metathesis ${ }^{35,36}$. Examples for radical transformations, such as the seminal copper catalyzed cyclization reported by Meisenheimer are rare, often limited by functional group tolerance and the formation of linear side products resulting from poor $E / Z$ regioselectivity in the cyclization step ${ }^{37-39}$.

Here, we reveal a versatile route to form helicenes via a directed, vinylacetylene mediated gas phase chemistry. In contrast a

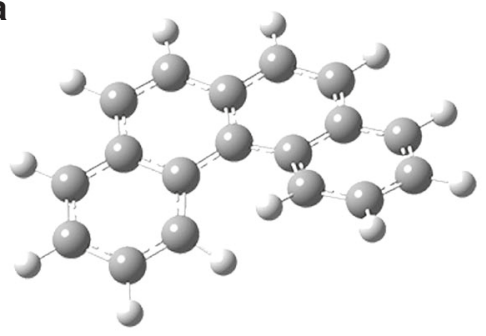

C

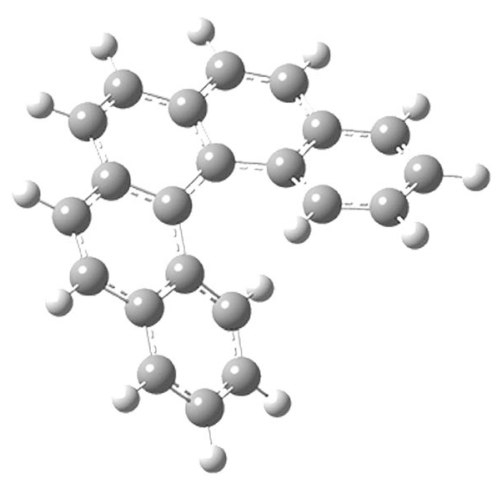

e

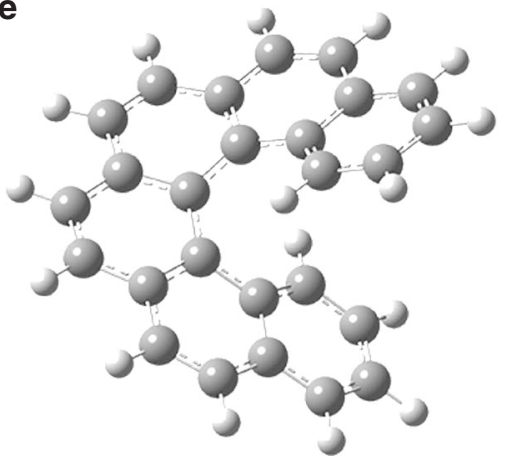

b

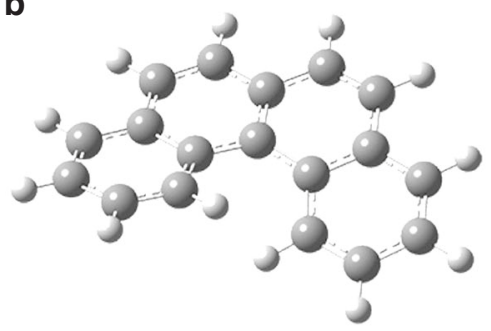

d

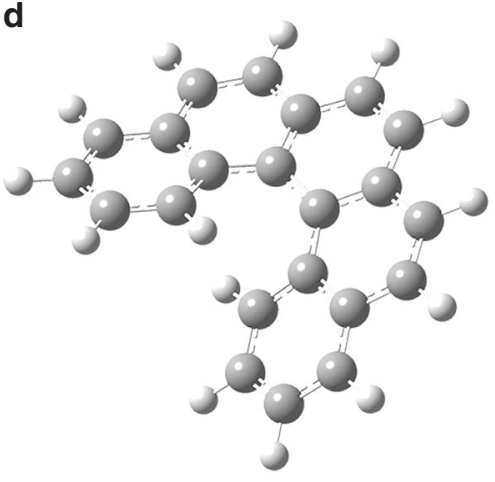

f

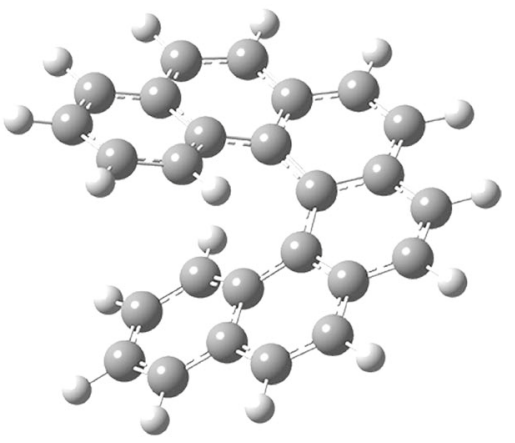

Fig. 1 Molecular structures of helicenes. a $(M)$-[4]-helicene; b $(P)$-[4]-helicene; c $(M)$-[5]-helicene; $\mathbf{d}(P)$-[5]-helicene; e $(M)$-[6]-helicene and $\mathbf{f}(P)$-[6]helicene 
to the aforementioned routes following solution chemistry and often ionic reaction intermediates $28,35,40,41$, the innovative gas phase synthesis encompasses low-barrier reactions through targeted, stepwise ring expansion mechanisms involving free radical reaction intermediates. Exploiting the simplest helicene as a benchmark, we reveal the hitherto unknown gas phase chemistry synthesizing [4]-helicene $\left(\mathrm{C}_{18} \mathrm{H}_{12} ; 228 \mathrm{amu}\right)$ along with atomic hydrogen ( $1 \mathrm{amu}$ ) via the bimolecular reaction of the 4 phenanthrenyl radical $\left(\left[\mathrm{C}_{14} \mathrm{H}_{9}\right]^{\bullet} ; 177 \mathrm{amu}\right)$ with vinylacetylene $\left(\mathrm{C}_{4} \mathrm{H}_{4} ; 52 \mathrm{amu}\right)$ (reaction (1)). Our combined experimental and $a b$ initio study exposes the prototype of a low-barrier reaction mechanism leading to the facile formation of the simplest helicene. [4]-helicene-an 18- $\pi$-electron aromatic molecule-was formed via a directed synthesis through molecular mass growth involving the reaction of an aromatic radical-4-phenanthrenylwith a single vinylacetylene molecule embracing a low-barrier ring-expansion via a resonance-stabilized free radical (RSFR) intermediate $\left(\mathrm{C}_{18} \mathrm{H}_{13}\right)$. This pathway represents a versatile reaction mechanism to build up even more complex helicenes such as [5]- and [6]-helicene via stepwise ring expansion through bimolecular gas phase reactions of an aryl radical with vinylacetylene. In more complex environments such as combustion flames, this pathway competes with a secondary reactions involving a hydrogen atom assisted isomerization of the thermodynamically less stable (E)-4-(but-1-en-3-yn-1-yl) phenanthrene isomer. Briefly, a chemical reactor was exploited to synthesize [4]helicene via the elementary gas phase reaction of the 4phenanthrenyl radical $\left(\left[\mathrm{C}_{14} \mathrm{H}_{9}\right]^{\circ}\right)$ with vinylacetylene $\left(\mathrm{C}_{4} \mathrm{H}_{4}\right)$. The reaction products were probed isomer-specifically in a molecular beam through fragment-free photoionization of the neutral products via tunable vacuum ultraviolet (VUV) light followed by detection of the ionized molecules in a reflectron time-of-flight mass spectrometer (Re-TOF-MS) (Methods).

$$
\left[\mathrm{C}_{14} \mathrm{H}_{9}\right]^{\cdot}+\mathrm{C}_{4} \mathrm{H}_{4} \rightarrow \mathrm{C}_{18} \mathrm{H}_{12}+\mathrm{H}^{\cdot}
$$

\section{Results}

Mass spectra results. Figure $2 \mathrm{a}$ displays a representative mass spectrum recorded at a photoionization energy of $9.50 \mathrm{eV}$ for the reaction of the 4-phenanthrenyl radical with vinylacetylene; reference spectra were also collected by substituting the vinylacetylene reactant with non-reactive helium carrier gas (Fig. 2b). A comparison of these data sets provides persuasive evidence on the synthesis of a molecule with the molecular formula $\mathrm{C}_{18} \mathrm{H}_{12}(228$ $\mathrm{amu}$ ) in the 4-phenanthrenyl-vinylacetylene reaction (Fig. 2a), which is clearly absent in the control study (Fig. 2b). Accounting for the molecular weight of the reactants and the products, it is evident that the $\mathrm{C}_{18} \mathrm{H}_{12}$ isomer(s) along with atomic hydrogen is the result of the bimolecular reaction of the 4-phenanthrenyl radical with vinylacetylene (reaction (1)). A signal for $\mathrm{C}_{16} \mathrm{H}_{10}$ (202 amu) is likely attributed to the reaction of 4-phenanthrenyl $\left(\left[\mathrm{C}_{14} \mathrm{H}_{9}\right]^{\circ} ; 177 \mathrm{amu}\right)$ with acetylene $\left(\mathrm{C}_{2} \mathrm{H}_{2} ; 26 \mathrm{amu}\right)$ and can be identified as pyrene and ethynylphenanthrene ${ }^{42}$ (Supplementary Fig. 1). Finally, signals at mass-to-charge ratios $(\mathrm{m} / \mathrm{z})$ of 259 $\left(\mathrm{C}_{13}{ }^{13} \mathrm{CH}_{9}{ }^{81} \mathrm{Br}^{+}\right), 258\left(\mathrm{C}_{14} \mathrm{H}_{9}{ }^{81} \mathrm{Br}^{+}\right), 257\left(\mathrm{C}_{13}{ }^{13} \mathrm{CH}_{9}{ }^{79} \mathrm{Br}^{+}\right), 256$ $\left(\mathrm{C}_{14} \mathrm{H}_{9}{ }^{79} \mathrm{Br}^{+}\right), 179\left(\mathrm{C}_{13}{ }^{13} \mathrm{CH}_{10}{ }^{+}\right), 178\left(\mathrm{C}_{14} \mathrm{H}_{10}{ }^{+}\right), 177\left(\mathrm{C}_{14} \mathrm{H}_{9}{ }^{+}\right.$/ $\left.\mathrm{C}_{14}{ }^{13} \mathrm{CH}_{8}{ }^{+}\right)$, and $176\left(\mathrm{C}_{14} \mathrm{H}_{8}{ }^{+}\right)$can be detected in both the 4phenanthrenyl-vinylacetylene and the 4-phenanthrenyl-helium experiments. Consequently, these molecules cannot be attributed to the reaction of 4-phenanthrenyl with vinylacetylene. Signal at $m / z=259-256$ can be associated with the non-pyrolyzed 4-bromophenanthrene precursor, whereas ion counts at $m / z=178$ and 179 are reflective of phenanthrene and ${ }^{13} \mathrm{C}$-phenanthrene generated through hydrogen abstraction by the 4-phenanthrenyl radical or hydrogen atom addition to this radical. Finally, a signal at $m / z=176$ and 177 is related to distinct phenanthryne isomers $(m / z=176)$ along with the unreacted 4-phenanthrenyl radical $\left(\left[\mathrm{C}_{14} \mathrm{H}_{9}\right]^{\bullet+} ; m / z=177\right.$ ) (Supplementary Fig. 1).

Photoionization efficiency spectra. Having identified hydrocarbon molecule(s) of the molecular formula $\mathrm{C}_{18} \mathrm{H}_{12}$ synthesized in the elementary reaction of the 4 -phenanthrenyl radical with vinylacetylene, we elucidate the nature of the structural isomer(s)

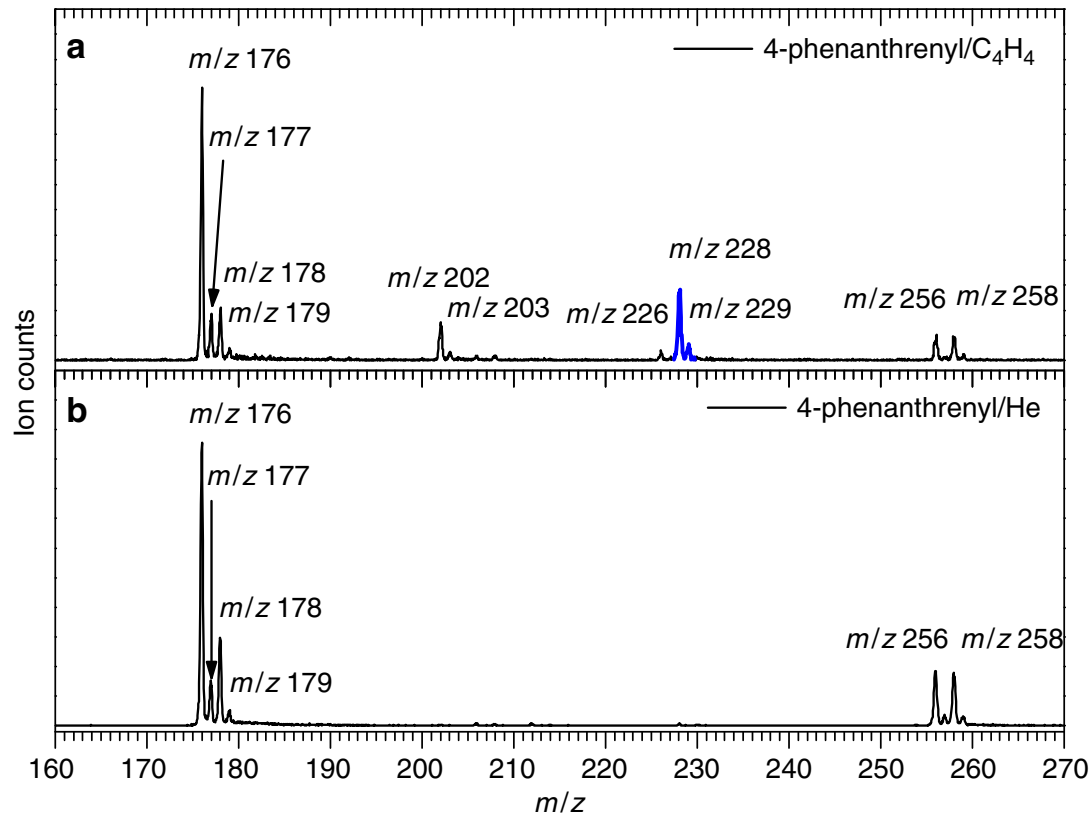

Fig. 2 Comparison of photoionization mass spectra recorded at a photoionization energy of $9.50 \mathrm{eV}$. a 4-phenanthrenyl $\left(\left[\mathrm{C}_{14} \mathrm{H}_{9}\right]^{*}\right)-$ vinylacetylene $\left(\mathrm{C}_{4} \mathrm{H}_{4}\right)$ system; b 4-phenanthrenyl $\left(\left[\mathrm{C}_{14} \mathrm{H}_{9}\right]^{\circ}\right)$ - helium (He) system. The mass peaks of the newly formed $\mathrm{C}_{18} \mathrm{H}_{12}(\mathrm{~m} / z=228)$ species along with the ${ }^{13} \mathrm{C}$ substituted counterparts $(m / z=229)$ are highlighted in blue 


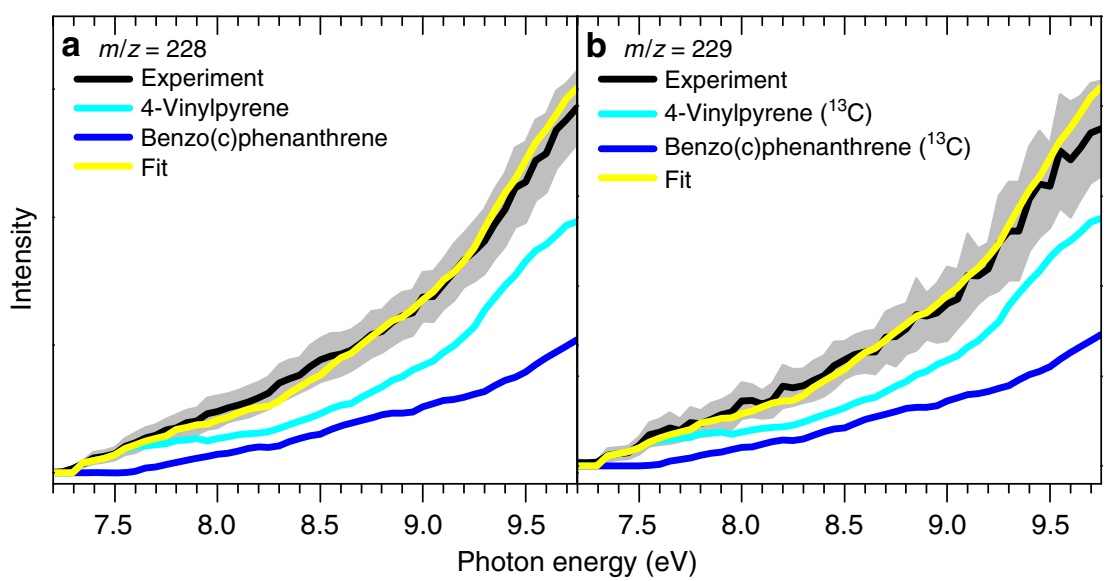

Fig. 3 Photoionization efficiency (PIE) curves relevant to the formation of [4]-helicene. a $\mathrm{m} / \mathrm{z}=228$ and $\mathbf{b} \mathrm{m} / \mathrm{z}=229$. Black: experimentally derived PIE curves; blue: [4]-helicene (benzo[c]phenanthrene) reference PIE curve; cyan: 4-vinylpyrene PIE curve; yellow: overall fit. The overall error bars (gray area) consist of two parts: $\pm 10 \%$ based on the accuracy of the photodiode and a $1 \sigma$ error of the PIE curve averaged over the individual scans

formed in this reaction. This necessitates a thorough examination of the corresponding photoionization efficiency (PIE) curve, which reports the intensity of the ion at $m / z$ of $228\left(\mathrm{C}_{18} \mathrm{H}_{12}{ }^{+}\right)$as a function of the photon energy from $7.20 \mathrm{eV}-9.75 \mathrm{eV}$ (Fig. 3a). These data have to be fit with a linear combination of distinct reference PIE curves of discrete $\mathrm{C}_{18} \mathrm{H}_{12}$ isomers: [4]-helicene (benzo[c]phenanthrene), 4-vinylpyrene, chrysene, benz $[a]$ anthracene, triphenylene, 4-((E)-but-1-en-3-yn-1-yl)phenanthrene, and 4-(but-3-en-1-yn-1-yl)phenanthrene (Supplementary Fig. 2). More explicitly, a linear combination of two reference curves is required to replicate the experimentally derived PIE curve for $m / z$ of 228 (black): [4]-helicene (blue) and 4vinylpyrene (red). The experimental and reference PIE curves for 4-vinylpyrene depict an onset of the ion signal at $7.30 \pm 0.05$ $\mathrm{eV}$. However, at photoionization energies higher than $7.60 \mathrm{eV}$, the PIE reference curve of 4-vinylpyrene cannot fit the experimental PIE curve alone, and ion counts are clearly lacking. To account for this mismatch, an incorporation of the PIE curve of [4]helicene is required. The overall fit (black) of the ion counts consists of [4]-helicene $(33 \pm 10 \%)$ and of 4 -vinylpyrene $(67 \pm$ $10 \%)$. It should be noted that inclusions of any contributions from 4-((E)-but-1-en-3-yn-1-yl)phenanthrene and 4-(but-3-en$1-y n-1-y l)$ phenanthrene do not improve the fit of the experimental data. This indicates that these isomers can be produced only at levels within the experimental error limits of the ion counts. We emphasize here that the aforementioned contributions to the fit of the experimental PIE curve do not represent the product branching ratios since absolute ionization cross sections are not available for any of the $\mathrm{C}_{18} \mathrm{H}_{12}$ isomers. A more detailed discussion on the computed product branching ratios based on computational fluid dynamics (CFD) simulations coupled with kinetic modeling of chemical reactions inside the reactor is given in the Supporting Information (Supplementary Note 2, Supplementary Fig. 5, Supplementary Tables 1-4). It is important to highlight that the PIE curve recorded at $m / z=229$ (Fig. 3b) matches after scaling the PIE curve of $m / z=228$. Consequently, the data at $m / z=229$ can be linked with ${ }^{13} \mathrm{C}$ substituted isomer $\left(\mathrm{C}_{17}{ }^{13} \mathrm{CH}_{12}\right)$ of [4]-helicene and 4-vinylpyrene with an overall abundance of close to $20 \%$ to account for the $1.1 \%{ }^{13} \mathrm{C}$ natural abundance. It is vital to highlight that the PIE curves of the $\mathrm{C}_{18} \mathrm{H}_{12}$ isomers are specifically linked to each specific isomer underlining that the co-existence of additional isomers in the molecular beam except [4]-helicene and 4-vinylpyrene would significantly alter the shape of the PIE; therefore, alternative $\mathrm{C}_{18} \mathrm{H}_{12}$ isomers can be eliminated to contribute to $m / z=228$.
Consequently, we conclude that only [4]-helicene and 4vinylpyrene account for the observed signal at $m / z=228$ within our error limits. The latter are based on the $1 \sigma$ error of the PIE curve averaged over multiple scans and the $\pm 10 \%$ error stated by the manufacturer as the accuracy of the photodiode.

\section{Discussion}

This study provides evidence that the simplest representative of the class of helicenes, i.e., [4]-helicene, can be formed in a directed synthesis through the gas phase elementary reaction of the 4-phenanthrenyl radical with vinylacetylene. Having identified [4]-helicene along with its 4-vinylpyrene isomer, we are attempting now to elucidate the underlying reaction mechanisms. Therefore, the experimental data are merged with electronic structure calculations on the $\mathrm{C}_{18} \mathrm{H}_{12}$ and $\mathrm{C}_{18} \mathrm{H}_{13}$ potential energy surfaces (PESs) (Fig. 4, Supplementary Fig. 4) (Methods). The calculations reveal that the vinylacetylene molecule approaches the 4-phenenthrenyl radical leading to the formation of two weakly stabilized distinct van-der-Waals complexes [1] and [2]; in each complex, the radical center at the $\mathrm{C} 4$ carbon atom is directed to the $\mathrm{H}_{2} \mathrm{C}=$ or $\mathrm{HCC}$ moiety of the vinylacetylene reactant at the $\mathrm{C} 1$ and $\mathrm{C} 4$ carbon atom, respectively. These complexes can isomerize through addition of the radical center to the carbon-carbon double and triple bond, respectively, forming a covalent carbon-carbon bond and intermediates [3] and [4] after passing through transition states located 14 and $17 \mathrm{~kJ} \mathrm{~mol}^{-1}$ above the van-der-Waals complex, respectively. In our earlier work $^{43,44}$, the addition of the smallest aryl radical, phenyl, to the $\mathrm{H}_{2} \mathrm{C}=$ moiety at the $\mathrm{C} 1$ carbon atom of vinylacetylene was found to be peculiar. There, a barrier to addition exists, but the corresponding transition state lies lower in energy than the separated reactants. Therefore, a barrier is present, however, the inherent transition state is located below the energy of the separated reactants and hence defined as a submerged barrier. The situation appears to be different for the 4-phenanthrenyl radical, where the barrier to form the carbon-carbon covalent bond is not submerged, but instead resides 6 to $9 \mathrm{~kJ} \mathrm{~mol}^{-1}$ above the separated reactants according to the G3(MP2,CC) and higher-level CCSD (T)/CBS calculations (Methods), respectively. The increase of the entrance barrier height in the 4-phenanthrenyl plus vinylacetylene reaction as compared to phenyl plus vinylacetylene is caused by the steric repulsion with the bay hydrogen atom in 4-phenanthrenyl, which hinders the approach of the $\mathrm{H}_{2} \mathrm{C}=$ group toward the radical site. The isomerization of [2] to [4] via 


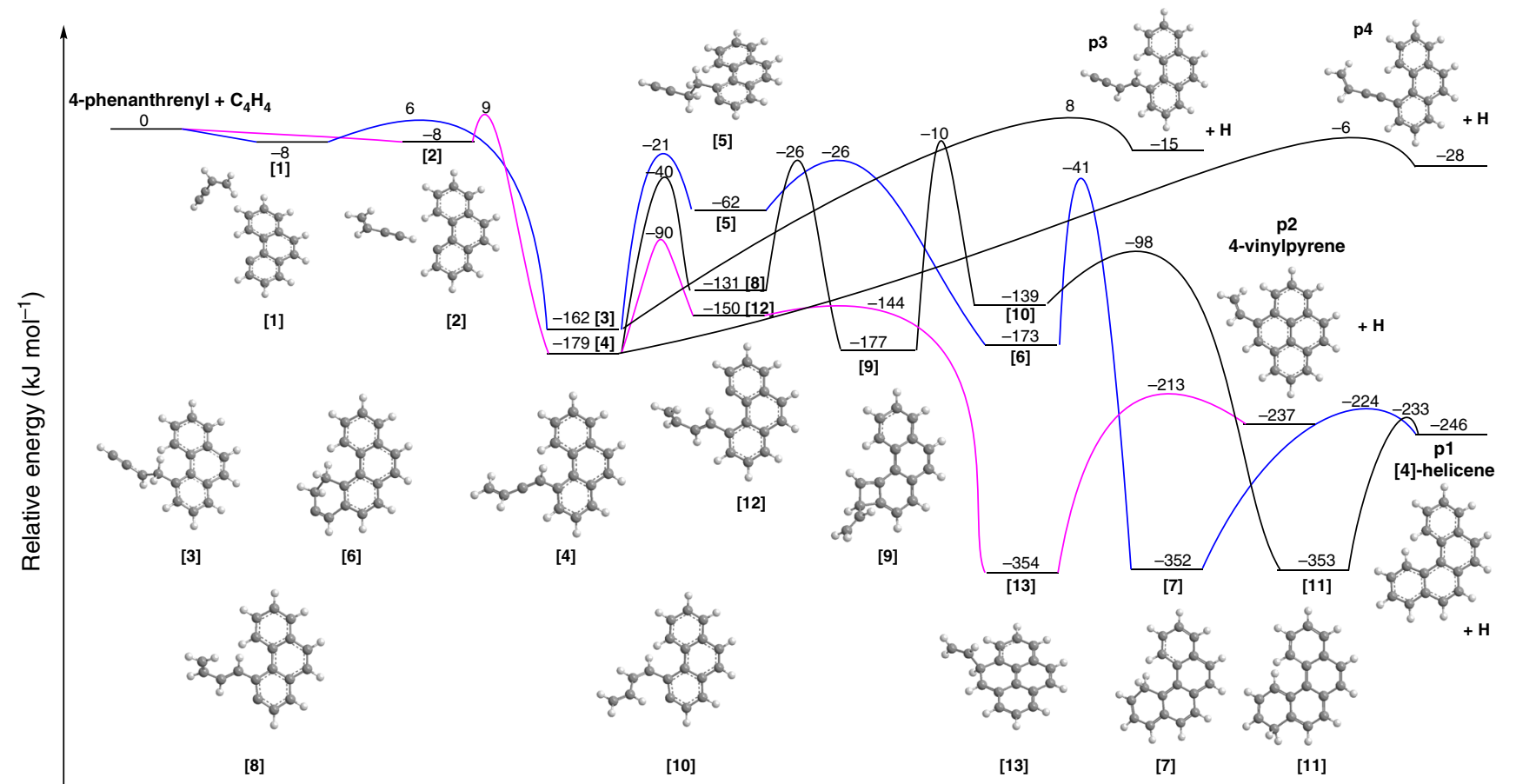

Fig. 4 Potential energy surface (PES) for the 4-phenanthrenyl $\left[\mathrm{C}_{14} \mathrm{H}_{9}\right]^{*}$ reaction with vinylacetylene $\left(\mathrm{C}_{4} \mathrm{H}_{4}\right)$. This PES was calculated at the $\mathrm{G} 3(\mathrm{MP2}, \mathrm{CC}) / /$ B3LYP/6-311G $(d, p)$ level of theory for the channels leading to [4]-helicene $\mathbf{p 1}$, 4-vinylpyrene p2, 4-((E)-but-1-en-3-yn-1-yl)phenanthrene p3, and 4-(but-3en-1-yn-1-yl)phenanthrene p4. The relative energies are given in $\mathrm{KJ} \mathrm{mol}^{-1}$

addition of the 4-phenanthrenyl radical to the HCC moiety proceeds via the transition state residing $9 \mathrm{~kJ} \mathrm{~mol}^{-1}$ above the energy of the separated reactants at the G3(MP2,CC)//B3LYP/6$311 \mathrm{G}(\mathrm{d}, \mathrm{p})$ level of theory, which is also higher than the corresponding energy in the phenyl plus vinylacetylene system, $5 \mathrm{~kJ}$ $\mathrm{mol}^{-1}$, but the steric hindrance for the HCC group approach is less than for the bulkier $\mathrm{H}_{2} \mathrm{C}=$ moiety.

The $\mathrm{C}_{18} \mathrm{H}_{13}$ intermediate [3] rearranges via a hydrogen shift from the $\mathrm{C} 3$ carbon atom of the phenanthrenyl moiety to the former vinylacetylene reactant forming intermediate [5] by switching the unpaired electron effectively from the side chain to the aromatic ring, which subsequently follows ring closure through a barrier of only $36 \mathrm{~kJ} \mathrm{~mol}^{-1}$ to intermediate [6]. The latter already mirrors the carbon skeleton of the target [4]-helicene and undergoes a hydrogen shift from the methylene group to the carbene center providing intermediate [7]. A closer look at this structure reveals that only an atomic hydrogen loss accompanied by aromatization is required to form [4]-helicene (p1) in an overall exoergic reaction $\left(246 \mathrm{~kJ} \mathrm{~mol}^{-1}\right)$. This hydrogen elimination proceeds almost perpendicularly to the molecular plane and passes a tight exit transition state located $22 \mathrm{~kJ} \mathrm{~mol}^{-1}$ above the separated products. Note that the existence of this tight exit transition state is reasonable because in the reverse reaction, the hydrogen atom has to add to a closed shell aromatic molecule, and the bond formation requires a significant change in electron density. This barrier to addition is of comparable magnitude as of $37 \mathrm{~kJ} \mathrm{~mol}^{-1}$ and $26 \mathrm{~kJ} \mathrm{~mol}^{-1}$ determined for the addition of atomic hydrogen to benzene and naphthalene-two benchmark aromatic systems ${ }^{45,46}$.

What is the fate of the second $\mathrm{C}_{18} \mathrm{H}_{13}$ intermediate [4]? The computations reveal that this intermediate can undergo two competing rearrangement pathways leading either to [4]-helicene or 4-vinylpyrene. The channel producing [4]-helicene is multistep and rather demanding both in terms of energy and entropy. It begins from a $[1,4]-\mathrm{H}$ shift from the attacked ring in the phenanthrene core to the bare carbon atom of the side chain in [4] forming [8] via a barrier of $139 \mathrm{~kJ} \mathrm{~mol}^{-1}$. Intermediate [8] cannot undergo immediate ring-closure because its side chain features a trans conformation with respect to the $\mathrm{C}=\mathrm{C}$ double bond. Rotation around the double bond is not feasible and hence the trans-cis isomerization to [10] occurs in two steps via intermediate [9] and involves a closure and opening of a four-member ring. However, the barriers along the $[\mathbf{8}] \rightarrow[\mathbf{9}] \rightarrow[\mathbf{1 0}]$ path are rather high. Next, [10] undergoes facile ring closure to [11] and a hydrogen atom loss in the latter produces [4]-helicene via an exit barrier of only $13 \mathrm{~kJ} \mathrm{~mol}^{-1}$. The alternative reaction channel starting from [4] is much more favorable. It begins with a [1,6]-H shift through the bay region of the phenanthrene core to the side chain forming [12] over a relatively low-barrier of $89 \mathrm{~kJ} \mathrm{~mol}^{-1}$. [12] is easily subjected to a six-member ring closure in the bay to form [13] and a hydrogen atom loss from [13] finally produces 4vinylpyrene (p2) - a structural isomer of [4]-helicene-in an overall exoergic reaction $\left(237 \mathrm{~kJ} \mathrm{~mol}^{-1}\right)$ with an exit barrier of 24 $\mathrm{kJ} \mathrm{mol}{ }^{-1}$. Consequently, the computational prediction of the formation of two structural isomers of $\mathrm{C}_{18} \mathrm{H}_{12}-$ [4]-helicene and 4 -vinylpyrene-is well matched by our experimental studies and directly reflects two distinct entrance channels to reaction via van-der-Waals complexes [1] and [2] and hence regioselective reaction dynamics leading to two discrete structural isomers thus defining a benchmark of a molecular mass growth process to PAHs. It should be noted that the initial covalently bound intermediates [3] and [4] can undergo hydrogen atom losses to form 1- and 4-phenanthrenyl-vinylacetylene isomers $\mathbf{p} 3$ and $\mathbf{p 4}$, respectively. These pathways are noticeable less favorable energetically than the formation pathways of [4]-helicene and 4vinylpyrene-more so that in the prototype phenyl plus vinylacetylene reaction-but may play a role at high temperatures due to a favorable entropic factor. To explore this possibility, we also 


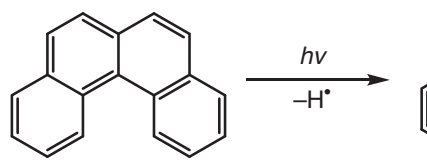<smiles>c1ccc2c(c1)ccc1ccccc12</smiles><smiles>C[13CH]</smiles><smiles>c1ccc2c(c1)ccc1ccc3ccccc3c12</smiles>

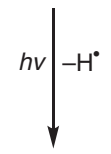
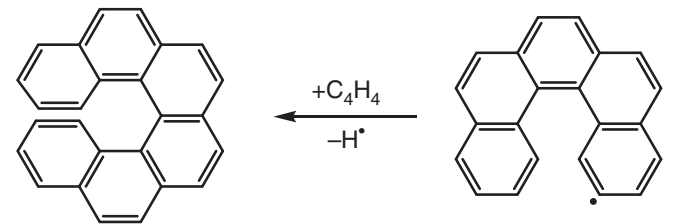

Fig. 5 Mechanism. Schematic presentation of a vinylacetylene mediated helicene propagation to [5]-helicene and [6]-helicene starting from [4]-helicene (benzo[c]phenanthrene)

conducted statistical Rice-Ramsperger-Kassel-Marcus Master Equation (RRKM-ME) calculations of product branching ratios at $1400 \mathrm{~K}$ (Supplementary Note 1). These calculations infer that in complex systems such as in combustion flames, [4]-helicene can be also formed via secondary reactions involving a hydrogen atom assisted isomerization of the (E)-4-(but-1-en-3-yn-1-yl) phenanthrene isomer (p3, Supplementary Fig. 4); however, in environments where bimolecular reactions dominate such as in circumstellar envelopes of carbon stars, secondary reactions are absent, and [4]-helicene is formed via the elementary reaction of the 4-phenanthrenyl radical $\left(\left[\mathrm{C}_{14} \mathrm{H}_{9}\right]^{\bullet}\right)$ with vinylacetylene $\left(\mathrm{C}_{4} \mathrm{H}_{4}\right)$.

The facile route to synthesize [4]-helicene $\left(\mathrm{C}_{18} \mathrm{H}_{12}\right)$ through the reaction of the 4-phenanthrenyl radical $\left(\left[\mathrm{C}_{14} \mathrm{H}_{9}\right]^{\bullet}\right)$ with vinylacetylene $\left(\mathrm{C}_{4} \mathrm{H}_{4}\right)$ represents a versatile pathway that could in principle be extended to higher helicenes. Our mechanistic studies reveal that the key step of the reaction is a low-barrier benzannulation through a resonance-stabilized free radical (RSFR) intermediate that leads to the simplest helicene. This pathway involving a bimolecular collision can serve as an alternative to other, commonly accepted gas phase reactions such as the traditional hydrogen abstraction-acetylene addition (HACA) route ${ }^{47,48}$. HACA, which has been invoked in an attempt to unravel the formation of PAHs in high-temperature environments such as in combustion flames ${ }^{49-51}$ and in outflows of the carbon-rich asymptotic giant branch (AGB) stars such IRC + $10216^{52}$, cannot lead to helicenes under single collision conditions. This pathway would rather lead to bay closure, but not to benzannulation as verified in the biphenyl $\left(\mathrm{C}_{12} \mathrm{H}_{9}\right)^{51}$-acetylene and 4-phenanthrenyl $\left(\left[\mathrm{C}_{14} \mathrm{H}_{9}\right]^{\bullet}\right)$-acetylene systems (Supplementary Fig. 3 $)^{42}$. Consequently, PAHs as complex as [4]-helicene $\left(\mathrm{C}_{18} \mathrm{H}_{12}\right)$ can be formed via a bimolecular reaction in circumstellar envelopes of dying carbon stars. However, in combustion flames such as of benzene ${ }^{53,54}$, where free hydrogen atoms are ubiquitous, secondary reactions via a hydrogen atom assisted isomerization of the (E)-4-(but-1-en-3-yn-1-yl)phenanthrene isomer likely also play an important role in the formation of [4]-helicene. In circumstellar environments, starting from [4]helicene, propagation via hydrogen loss by photodissociation followed by reaction with vinylacetylene provides an exceptional route to [5]-helicene and eventually to [6]-helicene (Fig. 5) thus supplying a directed, stepwise synthesis of racemic, helicallyshaped three-dimensional nanostructures via elementary neutralneutral reactions.

\section{Methods}

Experimental. The experiments were carried out at the Advanced Light Source (ALS) at the Chemical Dynamics Beamline (9.0.2.) utilizing a high-temperature chemical reactor consisting of a resistively-heated silicon carbide ( $\mathrm{SiC}$ ) tube of 20 $\mathrm{mm}$ length and $1 \mathrm{~mm}$ inner diameter ${ }^{50,51,55}$. This reactor is integrated into a molecular beam apparatus operated with a Wiley-McLaren reflectron time-of-flight mass spectrometer (Re-TOF-MS). This setup is designed to explore elementary chemical reactions to mimic $\mathrm{PAH}$ growth in situ through the reaction of aromatic radicals. In detail, 4-phenanthrenyl radicals $\left[\mathrm{C}_{14} \mathrm{H}_{9}\right]^{\bullet}$ were generated in situ via pyrolysis of the 4-bromophenanthrene precursor $\left(\mathrm{C}_{14} \mathrm{H}_{9} \mathrm{Br}\right)$ seeded in vinylacetylene/helium $\left(5 \% \mathrm{C}_{4} \mathrm{H}_{4} ; 95 \% \mathrm{He}\right.$; Airgas) carrier gas at a pressure of $300 \mathrm{Torr}$ in the entrance of the reactor. Accurate estimation of the concentration of $\mathrm{C}_{14} \mathrm{H}_{9} \mathrm{Br}$ in the incipient molecular beam is difficult because the vapor pressure of this precursor is not known but the results of the computational fluid dynamics simulations and kinetic modeling (Supplementary Note 2, Supplementary Fig. 5 and Supplementary Tables 1-4) are consistent with experiment at the level of $\mathrm{C}_{14} \mathrm{H}_{9} \mathrm{Br}$ concentration of $1-5 \%$. The temperature of the $\mathrm{SiC}$ tube was monitored using a Type-C thermocouple and was operated at $1400 \pm 10 \mathrm{~K}$. At this temperature, 4-bromophenanthrene dissociates to the 4-phenanthrenyl radical plus atomic bromine in situ followed by the reaction of the aromatic radical with vinylacetylene. The reaction products were expanded supersonically and passed through a 2-mm diameter skimmer located 10 $\mathrm{mm}$ downstream of the reactor and enter the main chamber, which houses the ReTOF-MS. The products within the supersonic beam were then photoionized in the extraction region of the mass spectrometer by exploiting quasi-continuous tunable synchrotron vacuum ultraviolet (VUV) light. VUV single photon ionization is a fragment-free ionization technique and is often described as a 'soft' ionization method $^{56,57}$ compared to the harsher conditions of electron impact ionization, the latter leading to excessive fragmentation of the parent ion. The ions formed via soft photoionization in the present experiments are extracted and introduced onto a microchannel plate detector through an ion lens. Photoionization efficiency (PIE) curves, which report ion counts as a function of photon energy from $7.20 \mathrm{eV}$ to 9.75 $\mathrm{eV}$ with a step interval of $0.05 \mathrm{eV}$ at a well-defined mass-to-charge ratio $(\mathrm{m} / z)$, were generated by integrating the signal collected at the specific $\mathrm{m} / z$ for the species of interest and normalized to the photon flux. The residence time in the reactor tube under our experimental condition are few hundreds of $\mu s^{58,59}$. Reference (control) experiments were also conducted by expanding neat helium carrier gas with the 4 bromophenanthrene precursor into the resistively-heated silicon carbide tube. No signals, which can be associated with the [4]-helicene of 4-vinylpyrene molecules at $m / z=228$ or 229 , was observed in these control experiments. Reference PIE curves of [4]-helicene, 4-vinylpyrene, (E)-4-(but-1-en-3-yn-1-yl)phenanthrene, and 4-(but3-en-1-yn-1-yl)phenanthrene were measured in the present work. [4]-Helicene (p1) was purchased from Sigma-Aldrich (98\%). The syntheses of 4-vinylpyrene (p2), (E)4-(but-1-en-3-yn-1-yl)phenanthrene (p3), and 4-(but-3-en-1-yn-1-yl) phenanthrene (p4) are described in the Supplementary Information (Supplementary Note 3, Supplementary Figs 6-12, and Supplementary Schemes 1-3).

Theoretical calculations. The energies and molecular parameters of the local minima and transition states involved in the reaction were computed at the G3 (MP2,CC)//B3LYP/6-311G(d,p) level of theory ${ }^{60-62}$ with a chemical accuracy of $3-6 \mathrm{~kJ} \mathrm{~mol}^{-1}$ for the relative energies and $0.01-0.02 \AA$ for bond lengths as well as $1-2^{\circ}$ for bond angles ${ }^{62}$. Additional higher-level calculations for the [1]-[3] transition state were performed using at the $\operatorname{CCSD}(\mathrm{T})$ level in the complete basis set (CBS) limit involving explicitly-correlated CCSD(T)-F12b and MP2-F12 
calculations $s^{63}$ with Dunning's correlation-consistent basis sets ${ }^{64}$, where the CCSD (T)/CBS total energies of the reactants and the transition state were approximated as follows:

$$
\begin{aligned}
\mathrm{E}(\operatorname{CCSD}(\mathrm{T}) / \mathrm{CBS})= & \mathrm{E}(\mathrm{CCSD}(\mathrm{T})-\mathrm{F} 12 \mathrm{~b} / \mathrm{cc}-\mathrm{pVDZ}-\mathrm{f} 12) \\
& +\mathrm{E}(\mathrm{MP} 2 / \mathrm{cc}-\mathrm{pVTZ}-\mathrm{f} 12) \\
& -\mathrm{E}(\mathrm{MP} 2 / \mathrm{cc}-\mathrm{pVTZ}-\mathrm{f} 12) .
\end{aligned}
$$

The GAUSSIAN $09^{63}$ and MOLPRO 2010 program packages ${ }^{64}$ were utilized for the ab initio calculations. The details of the statistical RRKM-ME calculations of the reaction rate constants and computational fluid dynamics simulations of the gas flow and chemical kinetics in the microreactor are provided in the Supplementary Information (Supplementary Notes 1 and 2, Supplementary Tables 1-4 and Supplementary Fig. 5).

\section{Data availability}

The data that support the plots within this paper and other findings of this study are available from the corresponding author upon reasonable request.

Received: 12 July 2018 Accepted: 27 February 2019

Published online: 03 April 2019

\section{References}

1. Chen, C.-F. \& Shen, Y. Helicene Chemistry: From Synthesis to Applications Ch. 1 (Springer, 2016).

2. Kato, K., Segawa, Y., Scott, L. T. \& Itami, K. A quintuple [6]helicene with a corannulene core as a C5 -symmetric propeller-shaped pi-system. Angew. Chem. Int. Ed. 57, 1337-1341 (2018).

3. Bruyère, A. et al. Intermixing of chirality and local structure in the second harmonic generation response of dibenzo[c] acridine helicene-like molecule thin films. J. Phys. Chem. C. 121, 24759-24765 (2017).

4. Aillard, P., Voituriez, A. \& Marinetti, A. Helicene-like chiral auxiliaries in asymmetric catalysis. Dalton. Trans. 43, 15263-15278 (2014).

5. Hoffmann, N. Photochemical reactions applied to the synthesis of helicenes and helicene-like compounds. J. Photochem. Photobiol. C. 19, 1-19 (2014).

6. Groen, M. B. \& Wynberg, H. Optical properties of some heterohelicenes. Absolute configuration. J. Am. Chem. Soc. 93, 2968-2974 (1971).

7. Samuel, K. Fundamental aspects and recent developments in optical rotatory dispersion and circular dichroism, F. Ciardelli and P. Salvadori, Eds, Heyden and Son, Ltd., London, New York, 1973. J. Poly. Sci., Poly. Lett. Ed. 12 360-361 (1974).

8. Chen, J. P., Gao, J. P. \& Wang, Z. Y. Long-distance chirality transfer in polymerization of isocyanides bearing a remote chiral group. Polym. Int. 44, 83-87 (1997).

9. Matsumoto, A. et al. Reversal of the sense of enantioselectivity between 1- and 2-aza[6] helicenes used as chiral inducers of asymmetric autocatalysis. Org. Biomol. Chem. 15, 1321-1324 (2017).

10. Demmer, C. S., Voituriez, A. \& Marinetti, A. Catalytic uses of helicenes displaying phosphorus functions. C. R. Chim. 20, 860-879 (2017).

11. Koetzner, L., Webber, M. J., Martinez, A., De Fusco, C. \& List, B. Asymmetric catalysis on the nanoscale: the organocatalytic approach to helicenes. Angew. Chem. Int. Ed. 53, 5202-5205 (2014).

12. Shen, Y. \& Chen, C. F. Helicenes: synthesis and applications. Chem. Rev. 112, 1463-1535 (2012)

13. Cahn, R. S., Ingold, C. \& Prelog, V. Specification of molecular chirality. Angew. Chem. Int. Ed. 5, 385-415 (1966)

14. Grimme, S. \& Peyerimhoff, S. D. Theoretical study of the structures and racemization barriers of $[n]$ helicenes $(n=3-6,8)$. Chem. Phys. 204, 411-417 (1996).

15. Janke, R. H., Haufe, G., Würthwein, E.-U. \& Borkent, J. H. Racemization barriers of helicenes: a computational study. J. Am. Chem. Soc. 118, 6031-6035 (1996).

16. Barroso, J. et al. Revisiting the racemization mechanism of helicenes. Chem. Commun. (Camb.). 54, 188-191 (2018).

17. Meisenheimer, J. \& Witte, K. Reduction von 2-nitronaphtalin. Eur. J. Inorg Chem. 36, 4153-4164 (1903).

18. Weitzenböck, R. \& Klingler, A. Synthese der isomeren kohlenwasserstoffe 1, 2-5, 6-dibenzanthracen und 3, 4-5, 6-dibenzphenanthren. Mon. für Chem. und Verwandte-. Teil. And. Wiss. 39, 315-323 (1918).

19. Newman, M. S. \& Lednicer, D. The synthesis and resolution of hexahelicene ${ }^{1}$. J. Am. Chem. Soc. 78, 4765-4770 (1956).

20. Scholz, M., Mühlstädt, M. \& Dietz, F. Chemie angeregter zustände. I. Mitt. Die richtung der photocyclisierung naphthalinsubstituierter thylene. Tetrahedron Lett. 8, 665-668 (1967).
21. Liu, L. \& Katz, T. J. Simple preparation of a helical quinone. Tetrahedron Lett 31, 3983-3986 (1990).

22. Willmore, N. D., Liu, L. \& Katz, T. J. A Diels-Alder route to [5]-and [6]helicenes. Angew. Chem. Int. Ed. 31, 1093-1095 (1992).

23. Willmore, N. D., Hoic, D. A. \& Katz, T. J. Diels-Alder reactions of asubstituted styrenes with p-benzoquinone. J. Org. Chem. 59, 1889-1891 (1994).

24. Katz, T. J. et al. An efficient synthesis of functionalized helicenes. J. Am. Chem Soc. 119, 10054-10063 (1997).

25. Fox, J. M., Goldberg, N. R. \& Katz, T. J. Efficient synthesis of functionalized [7]helicenes. J. Org. Chem. 63, 7456-7462 (1998).

26. Nuckolls, C., Katz, T. J., Katz, G., Collings, P. J. \& Castellanos, L. Synthesis and aggregation of a conjugated helical molecule. J. Am. Chem. Soc. 121, 79-88 (1999).

27. Paruch, K. et al. First friedel-Crafts diacylation of a phenanthrene as the basis for an efficient synthesis of nonracemic [7] helicenes. J. Org. Chem. 65, 7602-7608 (2000)

28. Songis, O. et al. A versatile synthesis of functionalized pentahelicenes. J. Org. Chem. 75, 6889-6899 (2010).

29. Caeiro, J., Peña, D., Cobas, A., Pérez, D. \& Guitián, E. Asymmetric catalysis in the $[2+2+2]$ cycloaddition of arynes and alkynes: Enantioselective synthesis of a pentahelicene. Adv. Synth. Catal. 348, 2466-2474 (2006).

30. Sehnal, P. et al. An organometallic route to long helicenes. Proc. Natl Acad. Sci. USA 106, 13169-13174 (2009).

31. Stará, I. G. et al. Transition metal catalysed synthesis of tetrahydro derivatives of [5]-, [6]- and [7] helicene. Tetrahedron Lett. 40, 1993-1996 (1999).

32. Teplý, F. et al. Synthesis of [5]-, [6]-, and [7] helicene via Ni (0)-or Co (I)catalyzed isomerization of aromatic cis, cis-dienetriynes. J. Am. Chem. Soc. 124, 9175-9180 (2002).

33. Kamikawa, K., Takemoto, I., Takemoto, S. \& Matsuzaka, H. Synthesis of helicenes utilizing palladium-catalyzed double $\mathrm{C}-\mathrm{H}$ arylation reaction. J. Org. Chem. 72, 7406-7408 (2007).

34. Xue, X. \& Scott, L. T. Thermal cyclodehydrogenations to form 6-membered rings: cyclizations of [5] helicenes. Org. Lett. 9, 3937-3940 (2007).

35. Collins, S. K., Grandbois, A., Vachon, M. P. \& Cote, J. Preparation of helicenes through olefin metathesis. Angew. Chem. Int. Ed. 45, 2923-2926 (2006).

36. McAtee, C. C., Riehl, P. S. \& Schindler, C. S. Polycyclic aromatic hydrocarbons via iron (iii)-catalyzed carbonyl-olefin metathesis. J. Am. Chem. Soc. 139, 2960-2963 (2017)

37. Harrowven, D. C., Guy, I. L. \& Nanson, L. Efficient phenanthrene, helicene, and azahelicene syntheses. Angew. Chem. Int. Ed. 45, 2242-2245 (2006).

38. Harrowven, D. C., Nunn, M. I. \& Fenwick, D. R. [5] helicenes by iterative radical cyclisations to arenes. Tetrahedron Lett. 43, 3189-3191 (2002).

39. Harrowven, D. C., Nunn, M. I. \& Fenwick, D. R. [5] helicenes by tandem radical cyclisation. Tetrahedron Lett. 43, 7345-7347 (2002).

40. Teply, F. et al. A convenient route to 2-hydroxy- and 2,15dihydroxyhexahelicene. Eur. J. Org. Chem. 2007, 4244-4250 (2007).

41. Murase, T., Suto, T. \& Suzuki, H. Azahelicenes from the oxidative photocyclization of boron hydroxamate complexes. Chem. - Asian J. 12, 726-729 (2017).

42. Zhao, L. et al. Pyrene synthesis in circumstellar envelopes and its role in the formation of 2D nanostructures. Nat. Astron. 2, 413-419 (2018).

43. Parker, D. S. N. et al. Low temperature formation of naphthalene and its role in the synthesis of PAHs (polycyclic aromatic hydrocarbons) in the interstellar medium. Proc. Natl Acad. Sci. USA 109, 53-58 (2012).

44. Mebel, A. M., Landera, A. \& Kaiser, R. I. Formation mechanisms of naphthalene and indene: From the interstellar medium to combustion flames. J. Phys. Chem. A 121, 901-926 (2017).

45. Mebel, A., Lin, M., Yu, T. \& Morokuma, K. Theoretical study of potential energy surface and thermal rate constants for the $\mathrm{C}_{6} \mathrm{H}_{5}+\mathrm{H}_{2}$ and $\mathrm{C}_{6} \mathrm{H}_{6}+\mathrm{H}$ reactions. J. Phys. Chem. A 101, 3189-3196 (1997).

46. Kislov, V. V., Islamova, N. I., Kolker, A. M., Lin, S. H. \& Mebel, A. M. Hydrogen abstraction acetylene addition and Diels-Alder mechanisms of PAH formation: a detailed study using first principles calculations. J. Chem. Theory Comput. 1, 908-924 (2005).

47. Frenklach, M., Clary, D. W., Gardiner, W. C. \& Stein, S. E. Detailed kinetic modeling of soot formation in shock-tube pyrolysis of acetylene. Proc. Combust. Inst. 20, 887-901 (1985).

48. Frenklach, M. \& Wang, H. Detailed modeling of soot particle nucleation and growth. Proc. Combust. Inst. 23, 1559-1566 (1991).

49. Parker, D. S., Kaiser, R. I., Troy, T. P. \& Ahmed, M. Hydrogen abstraction/ acetylene addition revealed. Angew. Chem. Int. Ed. 53, 7740-7744 (2014).

50. Parker, D. S. N. et al. Unexpected chemistry from the reaction of naphthyl and acetylene at combustion-like temperatures. Angew. Chem. Int. Ed. 54, 5421-5424 (2015)

51. Yang, T. et al. HACA's heritage: A free-radical pathway to phenanthrene in circumstellar envelopes of asymptotic giant branch stars. Angew. Chem. Int. Ed. 56, 4515-4519 (2017) 
52. Cherchneff, I. The inner wind of IRC +10216 revisited: New exotic chemistry and diagnostic for dust condensation in carbon stars. $A$ \& $A$ 545, A12/ 11-A12/14 (2012).

53. Marsh, N. D. et al. Newly identified products of benzene droplet combustion: Polycyclic aromatic hydrocarbons of three to ten rings. Polycycl. Aromat. Compd. 25, 227-244 (2005).

54. Comandini, A., Malewicki, T. \& Brezinsky, K. Chemistry of polycyclic aromatic hydrocarbons formation from phenyl radical pyrolysis and reaction of phenyl and acetylene. J. Phys. Chem. A 116, 2409-2434 (2012).

55. Zhang, F. et al. A VUV photoionization study of the formation of the indene molecule and its isomers. J. Phys. Chem. Lett. 2, 1731-1735 (2011).

56. Qi, F. Combustion chemistry probed by synchrotron VUV photoionization mass spectrometry. Proc. Combust. Inst. 34, 33-63 (2013).

57. Cool, T. A. et al. Photoionization mass spectrometer for studies of flame chemistry with a synchrotron light source. Rev. Sci. Instrum. 76, 094102 (2005).

58. Zhao, L. et al. VUV photoionization study of the formation of the simplest polycyclic aromatic hydrocarbon: Naphthalene $\left(\mathrm{C}_{10} \mathrm{H}_{8}\right)$. J. Phys. Chem. Lett. 9, 2620-2626 (2018).

59. Guan, Q. et al. The properties of a micro-reactor for the study of the unimolecular decomposition of large molecules. Int. Rev. Phys. Chem. 33 447-487 (2014).

60. Curtiss, L. A., Raghavachari, K., Redfern, P. C., Rassolov, V. \& Pople, J. A. Gaussian-3 (G3) theory for molecules containing first and second-row atoms. J. Chem. Phys. 109, 7764-7776 (1998).

61. Baboul, A. G., Curtiss, L. A., Redfern, P. C. \& Raghavachari, K. Gaussian-3 theory using density functional geometries and zero-point energies. J. Chem. Phys. 110, 7650-7657 (1999).

62. Curtiss, L. A., Raghavachari, K., Redfern, P. C., Baboul, A. G. \& Pople, J. A. Gaussian-3 theory using coupled cluster energies. Chem. Phys. Lett. 314, 101-107 (1999).

63. Frisch, M. J. et al. Gaussian 09, revision A.02 (Gaussian Inc., CT) (2009).

64. Werner, H. J. et al. MOLPRO, version 2010.1, http://www.molpro.net. (University College Cardiff Consultants Ltd., UK, 2010).

\section{Acknowledgements}

This work was supported by the US Department of Energy, Basic Energy Sciences DEFG02-03ER15411 (experimental studies) DE-FG02-04ER15570 (computational studies and synthesis of 4-vinylpyrene, (E)-4-(but-1-en-3-yn-1-yl)phenanthrene, and 4-(but-3 en-1-yn-1-yl) phenanthrene) and DE-SC0010409 (synthesis of precursor molecules) to the University of Hawaii, Florida International University and the University of California Berkeley, respectively. B.X. U.A., W.L. and M.A. are supported by the Director Office of Science, Office of Basic Energy Sciences, of the U.S. Department of Energy under Contract No. DE-AC02-05CH11231, through the Gas Phase Chemical Physcis Program, Chemical Sciences Division. The Advanced Light Source is also supported through the same contract. Ab initio calculations of the $\mathrm{C}_{18} \mathrm{H}_{13}$ PES relevant to the reaction of 4-phenanthrenyl radical with vinylacetylene and simulations of the gas flow and kinetics in the microreactor at Samara University were supported by the Ministry of Education and Science of the Russian Federation under Grant No. 14.Y26.31.0020. A.H. $\mathrm{H}$. is supported by the Presidential Fellowship from FIU.

\section{Author contributions}

R.I.K. designed the experiment; D.J., G.V. and F.R.F. synthesized the reactant; A.H.H. and S.F.W. synthesized the calibration compounds; L.Z., B.X., U.A. and W.L. carried out the experimental measurements; M.A. supervised the experiment; L.Z. performed the data analysis; M.E., E.K.B., V.N.A., M.V.Z., A.N.M. and A.M.M. carried out the theoretical analysis; R.I.K., A.M.M. and M.A. discussed the data; R.I.K. and A.M.M. wrote the manuscript.

\section{Additional information}

Supplementary Information accompanies this paper at https://doi.org/10.1038/s41467019-09224-8.

Competing interests: The authors declare no competing interests.

Reprints and permission information is available online at http://npg.nature.com/ reprintsandpermissions/

Journal peer review information: Nature Communications thanks the anonymous reviewers for their contribution to the peer review of this work. Peer reviewer reports are available.

Publisher's note: Springer Nature remains neutral with regard to jurisdictional claims in published maps and institutional affiliations.

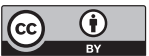

Open Access This article is licensed under a Creative Common Attribution 4.0 International License, which permits use, sharing, adaptation, distribution and reproduction in any medium or format, as long as you give appropriate credit to the original author(s) and the source, provide a link to the Creative Commons license, and indicate if changes were made. The images or other third party material in this article are included in the article's Creative Commons license, unless indicated otherwise in a credit line to the material. If material is not included in the article's Creative Commons license and your intended use is not permitted by statutory regulation or exceeds the permitted use, you will need to obtain permission directly from the copyright holder. To view a copy of this license, visit http://creativecommons.org/ licenses/by/4.0/.

(c) The Author(s) 2019 